\title{
OPTIMIZATION OF DITHIONITE BLEACHING OF HIGH YIELD BAGASSE PULP
}

\author{
MOHAMED EL-SAKHAWY, AMAL H. ABD EL-KADER, TAMER Y. A. FAHMY, \\ ESSAM S. ABD EL-SAYED and NESRINE F. KASSEM \\ National Research Center, Cellulose and Paper Department, El-Tahrir Str., \\ Dokki, Cairo, P.O. 12622, Egypt \\ ¿Corresponding author: M. El-Sakhawy,elsakhawy@yahoo.com
}

Received December 3, 2020

\begin{abstract}
Non-wood raw materials are an essential fiber source in regions where forest resources are limited. Therefore, chemimechanical high-yield bagasse pulp was prepared and then bleached with a dithionite bleaching agent. One- and twostage bleaching of the pulp was carried out by using sodium dithionite (Y) as a sole bleaching agent, or after bleaching with hydrogen peroxide to achieve high brightness for the prepared pulp. Different parameters, such as consistency, concentration, temperature, time and $\mathrm{pH}$ were investigated. The effect of various additives, such as diethylenetriaminepentaacetic acid (DTPA) as chelating agent or Zn compounds and hexamethylenetetramine to stabilize the bleaching solution, was studied. The effect of dissolved oxygen in liquor was also considered.
\end{abstract}

Keywords: dithionite bleaching, hydrogen peroxide bleaching, chelating agent, high yield pulp, bagasse

\section{INTRODUCTION}

The sugarcane industry is one of the oldest in Egypt. More than 16 million tons of canes are cultivated annually in Upper Egypt. ${ }^{1}$ Usually, sugar factories are located near the cane growing areas. The main sugarcane (Saccharum officinarum) residue (bagasse) is an extremely important raw material used for the pulp and paper industry, especially in developing countries where forests are limited and wood is expensive. ${ }^{2}$ Non-wood fibers are appropriate for the smaller mills, and adequate for limited markets in developing countries. Also, bagasse is used for different purposes in different sugar mills, such as for steam and power generation, and in the production of fiberboard. ${ }^{3}$ The main advantage of bagasse for the paper industry is its ready accessibility, in a clean condition, from the production of sugar. $^{4}$

The composition of bagasse includes about $44 \%$ cellulose, $28 \%$ hemicelluloses, $23 \%$ lignin, $1.5 \%$ ash, and $3.5 \%$ other components. ${ }^{5}$ The acid hydrolysis method could be used to isolate the cellulose from bagasse, followed by an alkaline pulping method. The reagents in hydrolysis attack the lignin macromolecule to break it into soluble low molecular weight units. $^{6}$ However, this reaction is not strong enough to eliminate all the lignin and hemicellulose residues; therefore bleaching as a further process can be used.

The production of pulp and paper from nonvirgin materials, such as bagasse, consumes less water, energy, chlorine and raw material, generating fewer greenhouse gases and methane emissions than in the case of virgin materials or wood. ${ }^{6}$ Furthermore, a typical mill for soda or Kraft pulp using bagasse generates energy in the form of steam and electricity from recovery boilers. ${ }^{1}$ High yield pulps are associated with paper mills of lower capital cost, and have a lower environmental impact during their manufacture as a result of little amounts of chemicals used. Furthermore, high yield pulps produce about twice the pulp per ton of raw material, in contrast to chemical pulps. ${ }^{7}$ Bagasse chemi-mechanical pulp (CMP) processes have been developed. ${ }^{8,9}$ Suitable chemical pretreatment of the bagasse is an essential step in the chemi-mechanical pulping process. The pretreatment step is important to soften the fiber structure, facilitate refining, save energy, improve pulp properties, and facilitate the bleaching step. ${ }^{10}$ Typically, the yield of bagasse mild soda pulp is in the range of $69-72 \%$, 
compared with lower than 50\% for Kraft bagasse pulp, while its strength properties are equivalent to those resulting from other chemical pulping processes. ${ }^{11}$

Semi-chemical bagasse pulp has a dark color due to its high lignin content, so it is used in products in which light color is not essential. Alternatively, it can be subjected a number of bleaching methods. Bleaching using molecular oxygen or ozone requires a relatively high temperature and the drawback of this process is a decreased quality of pulp, when the degree of delignification is $40-45 \% .{ }^{12}$ The chlorine-based bleaching techniques are increasingly being replaced by chlorine-free bleaching agents and oxygen-based reagents. ${ }^{13}$ The bleaching agents used to bleach pulp include chlorine dioxide, peracetic acid, hydrogen peroxide, and using alkali and Caro's acid. ${ }^{14}$ Hydrogen peroxide is a common chlorine-free alternative.

Sodium dithionite was considered in this study for high-yield pulp bleaching. Sodium dithionite has an odor similar to sulfur dioxide and about $50 \%$ of mechanical pulps are bleached by using sodium dithionite. ${ }^{15}$ Sodium dithionite is a pale yellow crystalline solid and is the active chemical in the dithionite (hydrosulfite) bleaching process. It is obtained as a solid or liquid, or even produced on-site through the reaction of sodium hydroxide with sodium borohydride. ${ }^{16}$ The pulp bleaching is achieved by the reaction of dithionite with the lignin chromophores to give a brighter pulp. It has been established through studies that high temperatures result in good bleaching, as high temperature favors the diffusion of dithionite ions into the fiber cell wall, which leads to a higher reaction rate than in the case of hydrogen peroxide. UV light reacts with the sodium dithionite pulp and reduces the brightness by inducing a yellowish color to the paper. ${ }^{17}$ Hydrogen peroxide and sodium dithionite are the main chemicals used, alone or in combination, for bleaching high yield pulps. The mechanical pulps could be bleached to 63\% ISO brightness using sodium hydrosulfite as a reducing bleaching agent. The high-yield cold soda pulps could be also bleached to a moderate brightness with sodium hydrosulfite. ${ }^{18}$ It is the most commonly used chemical when a brightness increase of up to 14 points is required.

The reaction of dithionite is:

$\mathrm{S}_{2} \mathrm{O}_{4}{ }^{2-}+2 \mathrm{H}_{2} \mathrm{O}----->2 \mathrm{HSO}_{3}^{-}+2 \mathrm{H}^{+}+2 \mathrm{e}^{-}$
Dithionites reduce quinone and aldehyde structures present in lignin macromolecules, which are oxidized to the sulfite ion, which decreases the light absorption coefficient of the paper, leading to an enhancement in brightness.

Dithionite bleaching has the advantages of high yield, small investment required, low load of BOD in wastewaters, and moderate chemical costs. Hydrogen peroxide with sodium hydroxide is used to produce the high $\mathrm{pH}$ necessary for producing the active per hydroxyl ion, $\mathrm{HOO}^{-7}$ ? $^{7}$

$\mathrm{H}_{2} \mathrm{O}_{2}+\mathrm{HOH}---->>\left(\mathrm{H}_{3} \mathrm{O}\right)^{+}+\mathrm{HOO}^{-}$

Alkalis promote reactions by the formation of conjugated carbonyl constructions, which form the substrates for the following attack by hydroperoxide anions. The perhydroxyl ion is a mild oxidant that does not change the structure and skeleton of lignin chromophores. Color reduction occurs by altering chromophoric groups, such as ortoquinones, resulting in fiber brightening. ${ }^{7}$ Hydrogen peroxide bleaching, followed by a hydrosulfite bleaching step, merges the oxidative and the reductive properties of peroxide and hydrosulfite, therefore, reducing the required chemicals for bleaching. Two-stage bleaching with peroxide and hydrosulfite can reach an 18 points increase in brightness. ${ }^{19}$ In general, peroxide bleaching provides greater brightness gains, but it is quite expensive and thus the hydrosulfite is more commonly utilized.

This work aims to optimize the dithionite bleaching of high yield bagasse pulp. To achieve appropriate pulp brightness and keep the high yield, the effects of different bleaching parameters and additives were studied.

\section{EXPERIMENTAL}

\section{Material}

Depithed bagasse, supplied by Edfo Mill, Egypt, was used in this study. Samples were conditioned in polyethylene bags for 48 hours, and then their moisture contents were determined. The elemental analysis of dry bagasse, including the ash, was performed and revealed the presence of $46.5 \%$ carbon, $6.5 \%$ hydrogen, and $46 \%$ oxygen.

\section{High yield bagasse pulping}

The depithed bagasse fibers were first pretreated by soaking overnight in $10 \%$ sodium hydroxide (based on bagasse) in a liquor ratio of 10:1, at room temperature. After chemical treatment, the bagasse was heated with the soaking liquor for two hours at $90{ }^{\circ} \mathrm{C}$. Then, bagasse fibrillation and refining were carried in a laboratory Valley beater, at $2 \%$ consistency for one hour. The pulp was disintegrated according to SCAN- 
M 2:64, at a stock consistency of $2 \%$, and screened. The resulting pulp suspension was collected and washed with water, and the pulp yield was determined. The collected fibers were then used for analysis and to make paper handsheets. The properties of different pulps were compared at constant pulp freeness of 40 SR.

\section{Sheet formation}

Paper sheets were prepared according to the S.C.A. standard, using a S.C.A. sheet former (AB Lorentzen and Wettre). In this apparatus, a sheet of $165 \mathrm{~mm}$ diameter $\left(214 \mathrm{~cm}^{2}\right.$ surface area) was formed. The weight of the oven-dry pulp used for every sheet was about $1.43 \mathrm{~g}$. After sheet formation, the sheet was pressed for 4 minutes (at $5 \mathrm{Kg} / \mathrm{cm}^{2}$ ) using a hydraulic press. The sheets were dried in a rotating cylinder drum at $120{ }^{\circ} \mathrm{C}$ and then conditioned at $65 \%$ relative humidity and temperature ranging between 18 and 20 ${ }^{\circ} \mathrm{C}$.

\section{Bleaching conditions}

Bleaching was performed in two steps.

The dithionite "hydrosulfite" step (Y): $2 \mathrm{~mL}$ of $\mathrm{Na}_{2} \mathrm{~S}_{2} \mathrm{O}_{4}(5 \%)$ was used for $100 \mathrm{~g}$ of pulp. $0.4 \mathrm{~mL}$ of hexamethylenetetramine (1\% in $1: 1 \mathrm{H}_{2} \mathrm{O}$ :glycerol) and $0.4 \mathrm{~mL}$ of diethylenetriaminepentaacetic acid (DTPA) ( $1 \%$ solution) were added at $60{ }^{\circ} \mathrm{C}$ and allowed to react for 60 minutes. The $\mathrm{pH}$ was adjusted to 6 by adding $0.2 \mathrm{~mL}$ of $10 \% \mathrm{NaOH}$ solution.

The hydrogen peroxide step (P): $2 \% \quad \mathrm{H}_{2} \mathrm{O}_{2}, 3 \%$ $\mathrm{NaOH}, 0.3 \%$ DTPA, $0.3 \% \mathrm{MgSO}_{4}$ and $2 \% \mathrm{Na}_{2} \mathrm{SiO}_{3}$ were used for bleaching at $70{ }^{\circ} \mathrm{C}$ for 2 hours.

\section{Paper aging}

The paper samples were subjected to thermal aging for two hours at $150{ }^{\circ} \mathrm{C}$. Besides the expression of Tappi brightness, Tongren and McIntyre suggested that the Kubelka-Munk K/S value would be a useful measure of discoloration:

$\mathrm{K} / \mathrm{S}=(1-\mathrm{R})^{2} / 2 \mathrm{R}$

where $\mathrm{K}$ is the light absorption coefficient, $\mathrm{S}$ is the light scattering coefficient, and $\mathrm{R}$ is the reflectance of an "infinitely thick" stack of papers.

The difference between the K/S value before (zero) and after accelerated aging (time, t) multiplied by 100 , i.e. $100\left[(\mathrm{~K} / \mathrm{S})_{\mathrm{t}}-(\mathrm{K} / \mathrm{S})_{0}\right]$, has been designated as the "post-color number" (PCN). ${ }^{20}$

\section{RESULTS AND DISCUSSION}

Table 1 illustrates the analysis results for the bagasse raw material and pulp, as well as the standard methods used for the analyses. Fiber length and diameters were found to be $1.51 \mathrm{~mm}$ and $21.40 \mu \mathrm{m}$, respectively. The pulping of bagasse by the chemi-mechanical method under the mentioned conditions offered a high pulp yield - of $74 \%$. Bleaching of this pulp by dithionite bleaching was investigated by varying different parameters $(\mathrm{pH}, \quad$ consistency, temperature, time, the concentration of $\mathrm{Na}_{2} \mathrm{~S}_{2} \mathrm{O}_{4}$, and various additives). The reported results for paper brightness are the mean value of five readings, with an average standard deviation of $3.91 \%$.

\section{Effect of pH on dithionite bleaching}

Figures 1 and 2 show the influence of $\mathrm{pH}$ during bleaching on yield and brightness, respectively. The bleaching solution without any adjustment has a $\mathrm{pH}$ of 4.5. In order to study the effect of $\mathrm{pH}$, it was adjusted to 3 or to 6-12 by adding $10 \% \mathrm{HCl}$ or $\mathrm{NaOH}$, respectively. The strong alkali in the bleaching liquor stabilizes the hydrosulfite and neutralizes the bagasse acids as they are released. It is well known that sodium hydrosulfite is unstable in an acidic medium and produces acidic substances as a result of selfdecomposition. $^{21}$ In the pretreatment of cold chemi-mechanical pulp, the alkali reduces the pulp brightness as a result of chromophores created in the lignin, which increases the light absorption coefficient, so bagasse chemimechanical pulp has a low brightness value. Figure 1 shows that the maximum pulps yield was attained at $\mathrm{pH} 7$ (neutral). Figure 2 shows that brightness (before and after aging) follows the same trend.

Table 1

Analyses of bagasse raw material and pulp

\begin{tabular}{lcccc}
\hline$\%$ & $\begin{array}{c}\text { Raw } \\
\text { bagasse }\end{array}$ & $\begin{array}{c}\text { Depithed } \\
\text { bagasse }\end{array}$ & $\begin{array}{c}\text { Bagasse } \\
\text { pulp }\end{array}$ & Method \\
\hline Moisture content & 8.0 & 8.0 & 9.7 & SCAN-C 3:78 \\
Ash content & 2.2 & 1.4 & 1.0 & Tappi T 211 om-86 \\
Lignin & 20 & 19 & 14 & Tappi T 222 om-88 \\
Holocellulose & 75 & 78 & 85 & Tappi T 9 wd-75 \\
$\quad$ Cellulose & 43 & 47 & 63 & Tappi T 203 om-88 \\
Pentosan & 28 & 24 & 19 & Tappi T 223 om-84 \\
\hline
\end{tabular}




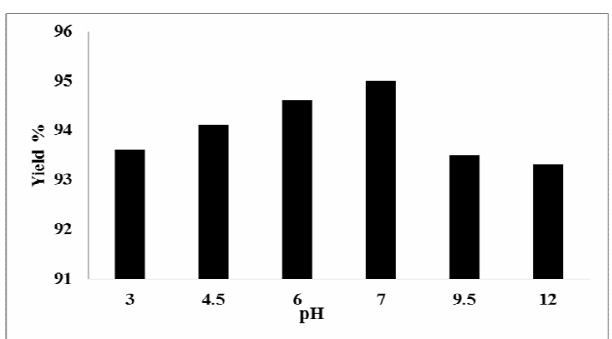

Figure 1: Effect of $\mathrm{pH}$ on the yield of bleached pulp

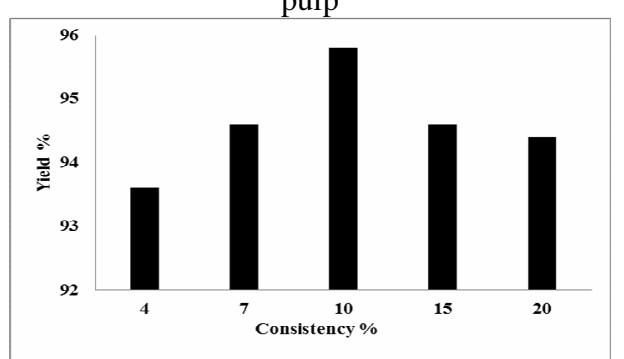

Figure 3: Effect of consistency on the yield of bleached pulp

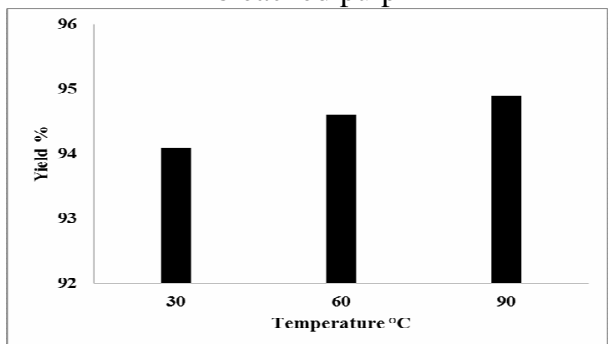

Figure 5: Effect of temperature on the yield of bleached pulp

One-stage dithionite bleaching under mild conditions provides an increase in ISO brightness by about 6-8 points, with optimum results at $\mathrm{pH}$ 6-7.

\section{Effect of consistency on dithionite bleaching}

The effect of consistency on the yield and brightness of the bleached pulp was plotted in Figures 3 and 4, respectively. It can be seen that low consistency (4\%) resulted in low yield and low brightness. The yield is clearly the highest for a consistency of $10 \%$ (Fig. 3). However, the brightness appears to be almost constant for a consistency range from 7 to $20 \%$, with a brightness increase of 8-9 ISO points.

\section{Effect of temperature on dithionite bleaching}

Figures 5 and 6 show the effect of temperature (room temperature, 60 and $90{ }^{\circ} \mathrm{C}$ ) on the yield and brightness during the dithionite bleaching. From Figure 5, it can be noticed that there is a slight increase in the yield with increasing temperature. Brightness showed a maximum

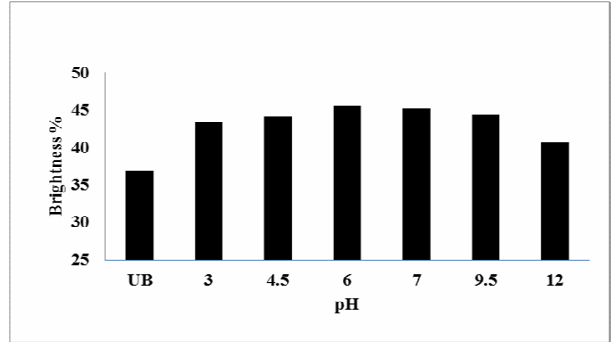

Figure 2: Effect of $\mathrm{pH}$ on the brightness of bleached pulp (UB - unbleached)

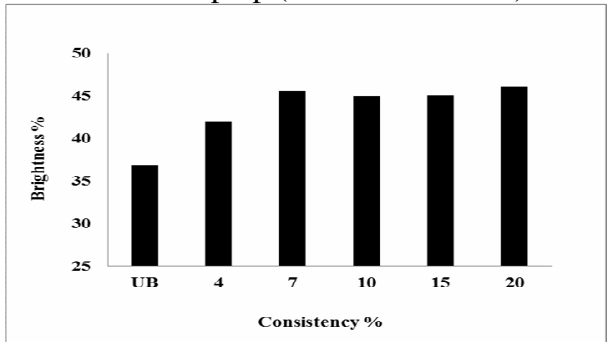

Figure 4: Effect of consistency on the brightness of bleached pulp (UB - unbleached)

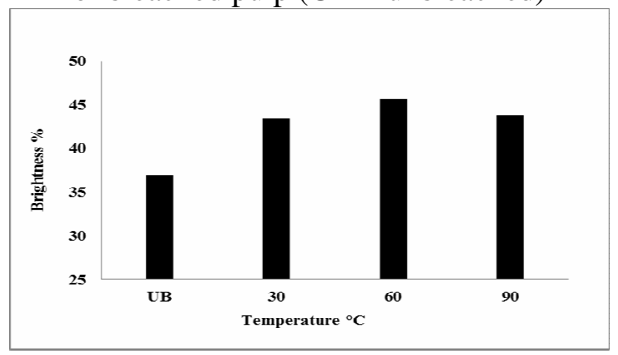

Figure 6: Effect of temperature on the brightness of bleached pulp (UB - unbleached)

value at a temperature of $60{ }^{\circ} \mathrm{C}$, with a brightness gain of 8.7 ISO points (Fig. 6).

\section{Effect of time on dithionite bleaching}

The effect of increasing the bleaching time from 20 to 90 minutes on the yield and brightness of the resulting pulp was plotted in Figures 7 and 8 , respectively. There was a marginal increase in both pulp yield and brightness values, with maximum bleaching for a reaction time of 60 minutes.

\section{Effect of $\mathrm{Na}_{2} \mathrm{~S}_{2} \mathrm{O}_{4}$ on dithionite bleaching}

Figures 9 and 10 show the effect of $\mathrm{Na}_{2} \mathrm{~S}_{2} \mathrm{O}_{4}$ percentage on the yield and brightness of the pulp. Increasing the percentage of $\mathrm{Na}_{2} \mathrm{~S}_{2} \mathrm{O}_{4}$ relative to pulp weight from 0.5 to $3 \%$ has a marginal effect on the pulp yield, while the brightness showed a slight increase.

\section{Two-stage bleaching}

Two-stage bleaching using hydrogen peroxide (P) and dithionite (Y) at $\mathrm{pH} 6$ or $\mathrm{pH} 12$ was 
investigated and compared with one-stage bleaching with dithionite only. Table 2 shows that one-stage dithionite bleaching increases the brightness by 8.7 points, while two-stage peroxide bleaching increases the brightness by 15.1 points.

Table 2 shows that the second dithionite bleaching stage provides a higher brightness gain, of 2.5-3.5 ISO points. Dithionite bleaching at $\mathrm{pH}$ 6 is preferred, especially during the second stage. This may be due to the creation of lignin chromophores in the alkaline medium. Acidic washing after alkaline dithionite bleaching improves the brightness value. The bleach chemicals consumption can be reduced by combining the oxidation and the reductive properties of peroxide and hydrosulfite bleach in

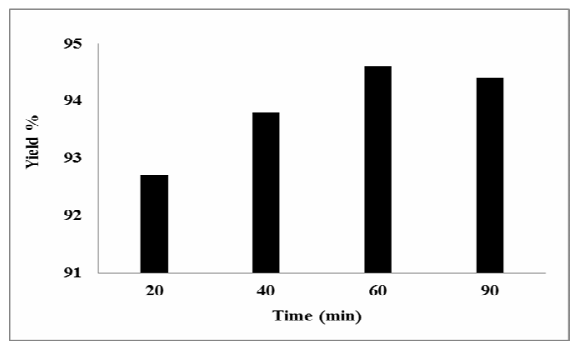

Figure 7: Effect of time on pulp yield

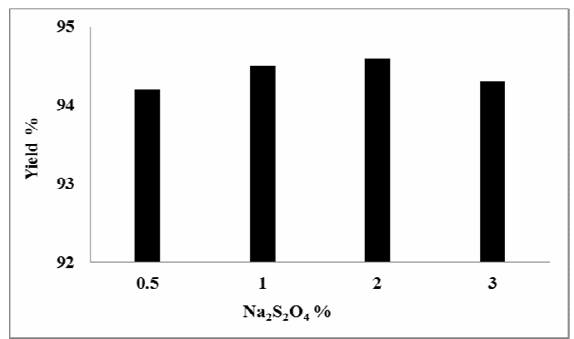

Figure 9: Effect of $\mathrm{Na}_{2} \mathrm{~S}_{2} \mathrm{O}_{4}$ on the yield of bleached pulp consecutive bleaching. ${ }^{22}$ The efficiency of the bleaching peroxide-dithionite sequence over that of hydrosulfite-peroxide is well established in the literature. ${ }^{23}$ So, the two-stage bleaching sequence peroxide-dithionite was evaluated. Peroxidedithionite bleaching provides a brightness increase of about 18.5 ISO points. The pulp brightness gained is stable after aging.

\section{Effect of different additives during dithionite bleaching}

Table 3 shows the effect of various additives during the dithionite bleaching under the same conditions as specified in the experimental part. Formalin was investigated because it is known as a stabilizer for the dithionite solution. ${ }^{24}$

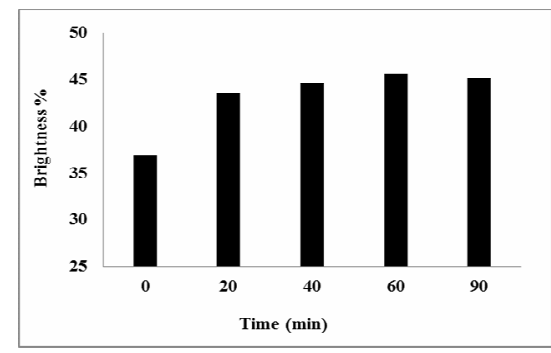

Figure 8: Effect of time on pulp brightness

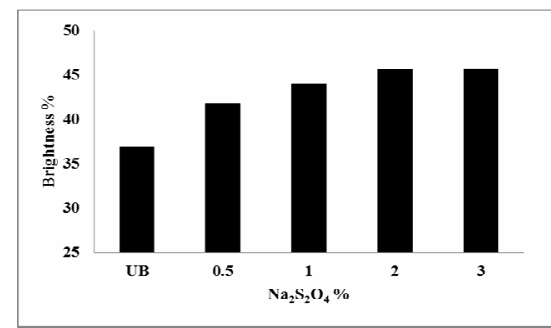

Figure 10: Effect of $\mathrm{Na}_{2} \mathrm{~S}_{2} \mathrm{O}_{4}$ on the brightness of bleached pulp (UB - unbleached)

Table 2

One- and two-stage bleaching by dithionite $(\mathrm{Y})$ and/or peroxide $(\mathrm{P})$

\begin{tabular}{lcccccc}
\hline $\begin{array}{l}\text { Bleaching } \\
\text { steps }\end{array}$ & $\begin{array}{c}\text { Yield, } \\
\%\end{array}$ & $\begin{array}{c}\text { Brightness, } \\
\%\end{array}$ & $\begin{array}{c}\text { Brightness } \\
\text { after aging }\end{array}$ & $\begin{array}{c}\mathrm{k} / \mathrm{s} \\
\text { initial }\end{array}$ & $\begin{array}{c}\mathrm{k} / \mathrm{s} \\
\text { after aging }\end{array}$ & PCN \\
\hline UB & 100 & 36.9 & 36.7 & 0.5395 & 0.5458 & 0.638 \\
Y6 & 94.6 & 45.6 & 45.3 & 0.3244 & 0.3302 & 0.576 \\
P & 90.1 & 52.0 & 52.1 & 0.2215 & 0.2201 & 0.134 \\
Y6/Y6 & 93.8 & 48.0 & 48.1 & 0.2816 & 0.2800 & 0.166 \\
Y6/Y12 & 91.8 & 47.1 & 47.0 & 0.2970 & 0.2988 & 0.175 \\
Y12/Y6 & 92.7 & 48.0 & 48.0 & 0.2816 & 0.2816 & 0 \\
Y12/Y12 & 91.9 & 46.2 & 46.2 & 0.3132 & 0.3132 & 0 \\
Y12/Y12 (acidic wash) & 91.6 & 47.0 & 46.6 & 0.2988 & 0.3059 & 0.713 \\
P/Y6 & 89.9 & 55.1 & 55.0 & 0.1829 & 0.1840 & 0.115 \\
P/Y12 & 89.1 & 55.5 & 55.3 & 0.1784 & 0.1806 & 0.225 \\
\hline
\end{tabular}

* UB = unbleached, Y6 and Y12 stand for dithionite bleaching at $\mathrm{pH} 6$ and 12, respectively, $\mathrm{P}=$ Peroxide,

*Acidic wash in $150 \mathrm{~mL}$ of $\mathrm{H}_{2} \mathrm{O}$ containing $0.5 \mathrm{~mL}$ of $\mathrm{HCl}(\mathrm{pH} 3)$ for $5 \mathrm{~min}$ 
Table 3

Effect of different additives on dithionite bleaching

\begin{tabular}{|c|c|c|c|c|c|c|}
\hline Additive, $\%$ & $\begin{array}{c}\text { Yield, } \\
\%\end{array}$ & $\begin{array}{c}\text { Brightness, } \\
\%\end{array}$ & $\begin{array}{l}\text { Brightness } \\
\text { after aging }\end{array}$ & $\begin{array}{c}\mathrm{k} / \mathrm{s} \\
\text { initial }\end{array}$ & $\begin{array}{c}\mathrm{k} / \mathrm{s} \\
\text { after aging }\end{array}$ & $\mathrm{PCN}$ \\
\hline UB & 100 & 36.9 & 36.7 & 0.5395 & 0.5458 & 0.6384 \\
\hline Without & 88.1 & 40.0 & 40.1 & 0.45 & 0.4473 & -0.2617 \\
\hline Formalin, 0.5 & 93.0 & 42.0 & 41.6 & 0.4004 & 0.4099 & 0.9447 \\
\hline Formalin, 1.0 & 93.7 & 42.0 & 42.6 & 0.4004 & 0.3867 & -1.3767 \\
\hline HMTA, 0.1 & 92.6 & 44.0 & 43.6 & 0.3563 & 0.3647 & 0.8425 \\
\hline HMTA, 0.2 & 95.1 & 44.0 & 44.0 & 0.3563 & 0.3563 & 0 \\
\hline HMTA, 0.4 & 93.9 & 44.0 & 43.8 & 0.3563 & 0.3605 & 0.4189 \\
\hline HMTA, 0.8 & 94.4 & 42.0 & 41.6 & 0.4004 & 0.4099 & 0.9447 \\
\hline DTPA, 0.2 & 92.8 & 43.0 & 43.0 & 0.3777 & 0.3777 & 0 \\
\hline DTPA, 0.4 & 92.0 & 46.0 & 45.0 & 0.3169 & 0.3361 & 1.9154 \\
\hline DTPA, 0.8 & 92.1 & 45.0 & 44.2 & 0.3361 & 0.3522 & 1.6111 \\
\hline HMTA, $0.4 \&$ DTPA, 0.4 & 94.6 & 45.6 & 45.3 & 0.3244 & 0.3302 & 0.5762 \\
\hline $\mathrm{ZnSO}_{4}, 0.1$ & 92.0 & 43.0 & 43.2 & 0.3777 & 0.3734 & -0.4384 \\
\hline $\mathrm{ZnSO}_{4}, 0.2$ & 92.1 & 44.0 & 44.2 & 0.3563 & 0.3522 & -0.4142 \\
\hline $\mathrm{ZnSO}_{4}, 0.4$ & 93.4 & 45.0 & 44.0 & 0.3361 & 0.3563 & 2.0253 \\
\hline $\mathrm{Na}_{2} \mathrm{SiO}_{3}, 0.2$ & 92.0 & 43.0 & 43.0 & 0.3777 & 0.3777 & 0 \\
\hline $\mathrm{Na}_{2} \mathrm{SiO}_{3}, 0.5$ & 92.7 & 43.2 & 43.4 & 0.3734 & 0.3690 & -0.4333 \\
\hline $\mathrm{Na}_{2} \mathrm{SiO}_{3}, 1.0$ & 93.8 & 43.6 & 43.5 & 0.3647 & 0.3669 & 0.2136 \\
\hline Poly phos., 0.1 & 91.2 & 42.4 & 42.2 & 0.3912 & 0.3958 & 0.4589 \\
\hline Poly phos., 0.3 & 92.2 & 43.5 & 43.5 & 0.3669 & 0.3669 & 0 \\
\hline Poly phos., 0.7 & 94.6 & 43.6 & 43.6 & 0.3647 & 0.3647 & 0 \\
\hline Poly phos., 1.0 & 97.4 & 44.5 & 44.6 & 0.3460 & 0.3440 & -0.202 \\
\hline With all & 95.5 & 42.0 & 41.9 & 0.4004 & 0.4028 & 0.2341 \\
\hline With all except formalin & 96.5 & 46.5 & 46.7 & 0.3077 & 0.3041 & -0.3605 \\
\hline $\mathrm{O}_{2}$ in $\mathrm{H}_{2} \mathrm{O}$ & 88.5 & 42.0 & 42.1 & 0.4004 & 0.3981 & -0.2328 \\
\hline Boiled $\mathrm{H}_{2} \mathrm{O}$ & 93.8 & 45.0 & 44.1 & 0.3361 & 0.3542 & 1.8176 \\
\hline
\end{tabular}

The hexamethylenetetramine (HMTA), 2\% to sodium hydrosulfite weight, avoids hydrogen sulfide formation during pulp bleaching, within the $\mathrm{pH}$ range of $4-11 .^{25}$ So, HMTA was evaluated at $0.1-0.8 \%$ to the pulp. It was found that even lower HMTA concentrations, of $0.1 \%$, provide an enhancement in pulp yield and increase the brightness values. Sodium dithionite solutions could be stabilized by a chelating agent at a concentration in solution of $0.3-1 \%$ by weight. ${ }^{26}$ DTPA, $0.2-0.8 \%$ to the pulp, was found to improve the pulp yield and brightness with the best addition of $0.4 \%$. A combination of HMTA and DTPA addition, both of $0.4 \%$, improves the pulp yield and brightness.

A sparingly soluble zinc compound was used to increase the stability of bleaching solutions containing dithionite. The effect of $0.1-0.4 \%$ $\mathrm{ZnSO}_{4}$ addition during bleaching shows a gradual increase in both pulp yield and brightness as $\mathrm{ZnSO}_{4} \quad$ concentration increases. Alkaline substances, such as sodium phosphate and sodium silicate, are usually used as stabilizers for sodium hydrosulfite. The effect of both sodium silicate
$\mathrm{Na}_{2} \mathrm{SiO}_{3}$, (0.2-1\% based on pulp weight), and sodium tripolyphosphate $(0.1-1 \%)$ added to the pulp during dithionite bleaching, was investigated. Table 3 shows that the pulp yield and brightness gradually increased as the additives concentration increases. The addition of all studied additives together during dithionite bleaching ( $0.4 \%$ of each) resulted in an obvious increase in the pulp yield and a minor increase in brightness, due to the distinct effect of formalin on lignin. When all additives were added, except formalin, both pulp yield and brightness were improved.

It is important in dithionite bleaching to mix the bleaching liquor well with the pulp and to keep the air (oxygen) in the pulp as low as possible. To study the effect of air on bleaching, two trials were carried out: one with liquor containing dissolved oxygen (previously bubbled with the air stream) and the other with liquor without dissolved oxygen (previously boiled water). The presence of air decreases both the pulp yield and brightness. Sodium hydrosulfite 
easily reacts with oxygen in the presence of moisture as follows:

$\mathrm{Na}_{2} \mathrm{~S}_{2} \mathrm{O}_{4}+\mathrm{O}_{2} \rightarrow \mathrm{Na}_{2} \mathrm{SO}_{3}+\mathrm{SO}_{3}$

It may be further decomposed by oxidation according to other reaction mechanisms. ${ }^{25}$

\section{CONCLUSION}

One-stage dithionite bleaching of high yield chemi-mechanical bagasse pulp provides an ISO brightness gain of about 6-9 points, with optimum results at $\mathrm{pH}$ 6-7. Maximum brightness was achieved at a bleaching temperature of $60{ }^{\circ} \mathrm{C}$ for 60 minutes. At least $1 \% \mathrm{Na}_{2} \mathrm{~S}_{2} \mathrm{O}_{4}$ (to pulp weight) was required to get a satisfying brightness increase. The second dithionite bleaching stage provides a higher brightness gain - of 2.5-3.5 ISO points. Peroxide-dithionite bleaching provides a brightness gain of about 18.5 ISO points.

Formalin was found to improve the pulp yield. HMTA, DTPA, $\mathrm{ZnSO}_{4}, \mathrm{Na}_{2} \mathrm{SiO}_{3}$ and/or sodium tripolyphosphate contribute to an improvement in pulp yield and increase the brightness values. The presence of air in the bleaching liquor decreases both the pulp yield and brightness. Pulp brightness shows stability after aging for two hours at $150{ }^{\circ} \mathrm{C}$.

\section{REFERENCES}

1 D. A. Nakhla and S. E. Haggar, Int. J. Agric. Policy Res., $\quad 2, \quad 321 \quad$ (2014), http://dx.doi.org/10.15739/IJAPR.003

2 E. S. Abd El-Sayed, M. El-Sakhawy and M. A. M. El-Sakhawy, Nord. Pulp Paper Res. J., 35, 215 (2020), https://doi.org/10.1515/npprj-2019-0064

3 M. K. Chauhan, S. Chaudhary and S. Kumar, Renew. Sustain. Energ. Rev., 15, 3445 (2011), https://doi.org/10.1016/j.rser.2011.04.033

4 S. Solomon, Sugar Tech., 18, 588 (2016), http://doi.org/10.1007/s12355-016-0494-2

5 G. J. de Moraes Rocha, V. M. Nascimento, A. R. Gonçalves, V. F. N. Silva and C. Martín, Ind. Crop. $\begin{array}{llll}\text { Prod., } & \text { 64, } & 52 & \text { (2015), }\end{array}$ http://doi.org/10.1016/j.indcrop.2014.11.003

6 E. I. Evstigneyev and S. M. Shevchenko, Wood Sci. Tech., 53, 7 (2019), http://doi.org/10.1007/s00226018-1059-1

7 T. G. Jones and J. D. Richardson, Appita J., 54, 265 (2001),

https://appita.com/login?wants=/resources/pub2001/ap pita_v54_no3

F. Potucek, M. Ríhová and B. Gurung, Cellulose Chem. Technol., 50, $489 \quad$ (2016), https://www.cellulosechemtechnol.ro/pdf/CCT34(2016)/p.489-496.pdf
9 A. Khakifirooz, F. Ravanbakhsh, A. Samariha and M. Kiaei, BioResources, 8, $21 \quad$ (2013), http://doi.org/10.15376/biores.8.1.21-30

10 R. Lanouette, J. Thibault and J. L. Valade, Tappi J., 81, 143 (1998), https://imisrise.tappi.org/TAPPI/Products/98/OCT/98O CT143.aspx

11 F. Yue, K. L. Chen and F. Lu, Molecules, 21, 85 (2016), http://doi.org/10.3390/molecules21010085

12 S. K. Tripathi, N. K. Bhardwaj and H. R. Ghatak, Cellulose Chem. Technol., 53, 105 (2019), http://doi.org/10.35812/CelluloseChemTechnol.2019.5 3.12

13 K. Anupam, V. Swaroop and P. S. Lal, J. Clean. Prod., 199, 420 (2018), http://doi.org/10.1016/j.jclepro.2018.07.125

14 N. Sharma, N. K. Bhardwaj and R. B. P. Singh, J. Clean. Prod., 256, 120338 (2020), http://doi.org/10.1016/j.jclepro.2020.120338

15 P. Malkavaara, J. P. Isoaho, R. Alén and J. Soininen, J. Chemomet., 14, 693 (2000), http://doi.org/10.1002/1099128X(200009/12)14:5/6\%3C693

16 J. Krishnan, S. Sunil Kumar and R. Krishna Prasad, Chem. Eng. Commun., 207, 837 (2020), http://doi.org/10.1080/00986445.2019.1630391

17 M. Paulsson and J. Parkås, BioResources, 7, 5995 (2012), http://doi.org/10.15376/biores.7.4.5995-6040

18 E. Svensson, H. Lennholm and T. Iversen, J. Pulp Pap. Sci., 24, 254 (1998), http://www.divaportal.org/smash/record.jsf?pid=diva2\%3A1195966\&d swid $=-3478$

19 M. El-Sakhawy, Polym. Degrad. Stabil., 87, 419 (2005),

https://doi.org/10.1016/j.polymdegradstab.2004.10.002

${ }^{20}$ Z. Zhou, A. S. Jääskeläinen, I. Adorjan, A. Potthast, P. Kosma et al., Holzforschung, 65, 289 (2011), http://doi.org/10.1515/hf.2011.047

21 J. P. Isoaho, J. K. Soininen and R. J. Alen, Appita $\begin{array}{lllll}J ., & 72, & 197 & \text { (2019), } \quad \text { https://appita.com/ }\end{array}$ login?wants=/resources/pub2019/appita_issue_no4

22 M. Fišerová, E. Opálená, J. Gigac and M. Stankovská, Wood Res., 63, 639 (2018), http://www.woodresearch.sk/articles.php? volume $=17 \&$ issue $=70$

${ }^{23}$ C. Daneault, C, Leduc and J. L. Valade, Appita J., 46, 429

(1993)

https://appita.com/login?wants=/resources/pub1993/ap pita_v46_no6

24 L. M. de Carvalho and G. Schwedt, J. Chromatog. A, 1099, $185 \quad$ (2005), https://doi.org/10.1016/j.chroma.2005.08.084

25 E. Gasana, P. Westbroek, K. De Wael, E. Temmerman, K. De Clerck et al., J. Electroanal. Chem., 553, 35 (2003), http://doi.org/10.1016/S00220728(03)00255-9

26 L. Lapierre, D. Pitre, R. Deshaye and J. Bouchard, Pulp Pap. Can., 102, 22 (2001). 